\title{
Connecting with Coworkers on Social Network Sites: Strategies, Social Norms and Outcomes on Work Relationships
}

\author{
Ariane Ollier-Malaterre \\ Université du Québec A Montréal \\ ollier.ariane@uqam.ca
}

\author{
Kassandra Luneau-de Serre \\ Complexe Évasion \\ kassandraluneau@levasion.com
}

\begin{abstract}
Although an increasing number of individuals are connected with their coworkers on social network sites (SNS) that are professional and personal (e.g., Facebook), little research has explored the outcomes of these connections on interpersonal relationships at work. Drawing on SNS research as well as on an existing typology of online boundary management strategies (i.e., "audience", "content", "custom" and "open"), we took an exploratory qualitative approach and interviewed all employees of 4 teams in diverse working environments. Our findings reveal that although interviewees' behaviors reflected the 4 strategies, there were gray zones, and the audience strategy veered off course. Almost all interviewees monitored their content disclosure through either content or custom strategies. Specific social norms regarding SNS emerged. The outcomes of connecting with coworkers on SNS were mostly positive, including liking, closeness, respect, and organizational citizenship behaviors toward individuals (OCBI). However, disliking, loss of respect and envy were also mentioned.
\end{abstract}

\section{Introduction}

This paper investigates the social and interpersonal implications of connecting with one's coworkers in cyberspace when the boundaries between the professional and personal social worlds are blurred. Long gone is the time when most work interactions took place in an offline work setting characterized by clear social norms about what it means to behave professionally $[1,2]$, and prescribed segmentation between the professional and personal realms [3]. Along with other technological advances facilitating the blurring of the boundaries between work and life, social network sites (SNS) such as Facebook, where people connect not only personally but also professionally, bridge our different social worlds.
Interactions on such SNS create context collapse [4] and a collision of people's professional and personal identities, which are simultaneously enacted rather than segmented as in most offline interactions [5].

Fifty-eight percent of U.S. employees report being connected with coworkers on Facebook, and 40.5\% with bosses [6]. Because SNS serve an important role for relationship development and maintenance [7], they have become social spaces in which interactions between coworkers may be consequential for interpersonal relationships at work. It is therefore important to understand the psychological and social impacts of this widespread technology which now contributes to frame interpersonal relationships at work.

Interpersonal interactions on SNS differ from faceto-face and from other computer-mediated interactions in specific ways that may be unsettling for individuals accustomed to seeing their audience and to adapt their behavior according to visual cues and well-established social scripts [8-10]. Whereas individuals in dyads and small groups face-to-face, phone or electronic communications may tailor their information disclosure and behaviors according to their audience, the default communication on SNS is one-to-many [11]. This affordance means that individuals can only imagine what their audience may be [10]. And because some of their connections do not interact with them frequently or at all, they may become a forgotten invisible audience [8]. As a result, individuals may share information that is appropriate for their intended audience [11] but not for their actual audience.

Coworkers and bosses, in particular, are likely to assess information shared on SNS differently than family members and personal friends, because many workplaces still pressure individuals to behave in rational and professional ways [1]. Publications on SNS may affect the way coworkers and bosses perceive an employee and in particular the respect and liking that they have for him or her [5]. However, the extent to which workplace norms extend to SNS interactions is unknown; while professional norms 
clearly apply to career-focused sites such as LinkedIn, Facebook was initially mostly viewed as personal but is now also used for work purposes, through the creation of professional pages, group pages, and the "Follow" affordance. Consequently, it is not clear what inappropriate SNS disclosures and behaviors constitute and what the consequences of these may be at work.

Given the importance of SNS in relationship building and maintenance $[7,12]$, and the relative lack of explicit social norms guiding appropriate behavior in this emerging social space, we believe that it is important for individuals and organizations to understand [1] how individuals navigate context collapse on SNS and specifically, what strategies they enact when they are connected with coworkers on SNS, [2] what social norms, old and new, may now characterize social media etiquette and [3] what outcomes these strategies and the observance or violation of social norms have on interpersonal relationships at work. The present research reports our findings on these three questions based on an exploratory qualitative in-depth study of 4 teams comprising between 3 and 5 coworkers, totaling 15 semi-structured interviews in diverse work settings. This study challenges and extends prior theoretical work on boundary management and identity navigation in cyberspace and opens up new areas of research in the information systems, communications, social psychology, and management fields.

\section{Navigating context collapse on SNS}

SNS such as Facebook that bring together personal and professional contacts are a double-edged sword for individuals who connect with coworkers. On one hand, they may open up opportunities insofar as they may help coworkers to see the whole person behind the coworker and thus build stronger multiplex relationships [13]. On the other hand, many employees hesitate before connecting with their coworkers, or worse, their boss, on Facebook [14, 15]. In addition, issues of privacy [8, 16] and of interpersonal surveillance [17] on social media have attracted scholarly and public attention. In this section, we will review what is known about the ways in which individuals manage work relationships on SNS.

\subsection{Online boundary management strategies}

The presentation of self on SNS is informed by identity expression and impression management concerns that are made complex by the blurring of the boundaries between professional and personal personae
[5, 18, 19]. Early work on SNS noted that individuals who felt pressured to accept requests from professional contacts used specific strategies in order to regulate their information disclosure to their coworkers: they censored the information they shared [20, 21], used a lowest common denominator approach [22], adjusted their profile visibility [23], disclosed different information to different individuals $[9,17,24]$, or created multiple profiles [25].

These strategies constitute online boundary work to the extent that they aim at recreating boundaries on SNS. More specifically, four types of online boundary management behaviors have been theorized based on identity presentation motives $[5,26]$ : (1) audience, i.e. individuals managing with whom they communicate on SNS, thereby excluding professional contacts from Facebook if necessary, (2) content, i.e. individuals monitoring what they communicate on SNS and what others post about them, (3) custom, i.e. individuals creating subgroups of contacts and tailoring the information they share to each subgroup via multiple profiles or lists, and (4) open, i.e. individuals embracing the social media transparency rhetoric and posting information as it comes to their mind without monitoring the content or controlling who might see it. Because this typology was theoretically derived and the four sets of behaviors were intended as ideal-types, it is possible, however, that the actual behaviors that individuals display toward their coworkers on SNS are more complex and comprise gray areas.

\subsection{Social norms on SNS}

Social norms are meant to regulate social interactions; they are formed through consensus and guide individuals in a group on attitudes and behaviors considered (in) appropriate in a given setting [27]. Holding up to group norms helps individuals to fit within the group [28, 29]. Whether SNS are a front stage public arena in which workplace and broader social norms apply [2], or a backstage arena in which private disclosure and behaviors are possible [31], is a disputed issue $[8,30]$. Therefore, it is unclear whether workplace norms apply on SNS or not.

Individuals learn about norms on SNS by trial and error, and by observing what their connections do [32]. It is still unclear, however, whether one should send requests to, or accept requests from, coworkers and bosses on Facebook. Although the site's terminology implies that it is meant to connect with "friends", actual friends constitute less than $40 \%$ of individuals' connections on Facebook [12]. Disclosure norms are also debatable: Facebook's affordances encourage individuals to volunteer a lot of personal information, 
yet 58\% of Facebook users report restricting access to their profiles and $44 \%$ report having removed content published on them by their connections [33]. In addition, disclosures on Facebook are not all authentic and people lie online for a variety of reasons, including securing acceptance from others, protecting their privacy, for fun or fantasy [34]. Because of the ambiguity surrounding SNS norms, norm violations may arise and impact interpersonal relationships [32].

\subsection{Outcomes of being connected with one's coworkers on SNS}

There is surprisingly little research on the outcomes of being connected with one's coworkers on SNS that blur boundaries between professional and personal identities. Research so far has examined whether connections on SNS expand social capital and in particular bridging social capital $[4,12]$ and the career consequences information disclosure on SNS [26, 35, 36]. A couple of studies have focused on the impact of such connections on the socialization of new hires [37, $38]$ and on job performance [39, 40]. However, there is very scant research on the consequences of connecting with coworkers on interpersonal relationships at work.

On one hand, it could be hypothesized that connecting with coworkers may increase interpersonal respect and liking, when self-disclosure reveals homophilous values and observance of group norms [5]. In fact, individuals who disclose more information and interact more on the internet are more liked by others [41]. In line with social psychology's findings that disclosure increases liking [42], research also found that intimate self-disclosures on SNS increase the feeling of connection between individuals; in addition, positive and entertaining self-disclosures also increased that feeling [11]. Another study found that boundary blurring created positive emotions for employees using an internal SNS [38].

On the other hand, norms violations may offend coworkers (e.g., when connection requests are ignored), disclosures may signal dissimilarity in values [43], and comments on coworkers' statuses and pages may be perceived as boundary violations, all of which can decrease interpersonal respect and liking among coworkers [5, 32]. In addition, malevolent behaviors that tamper with coworkers' online reputation may downright damage relationships at work [44]. Furthermore, SNS may also nurture jealousy among individuals [45] and thus possibly among coworkers.

\section{Method}

In line with our exploratory objectives, we chose a qualitative research design in order to collect rich data. We performed a content analysis of the data using a modified grounded theory approach; rather than being completely inductive as the original grounded theory approach was [46], our approach was abductive in that we iteratively read the comments and went back to the literature [47, 48].

We identified teams in which coworkers were connected on SNS and in particular Facebook. We targeted small teams ( 3 to 8 coworkers) so that we could interview all members in each team and triangulate information across team members.

\subsection{Sample}

We selected contrasted work environments with managers and professionals as well as middle-range and low-income employees. We recruited the teams through our personal connections after having gained ethical approval from our institutional board. The sample is comprised of 15 individuals working in 4 different teams across Canada.

The teams we interviewed were (a) 5 employees, including two supervisors, in a cosmetics and hair products multinational, (b) 4 employees in a not-forprofit organization helping students to find employment, (c) 3 employees of a retail store specialized in equestrian products and (d) a hairdresser's salon with 3 members including the owner and a trainee. All interviewees were connected with at least one of their colleagues on a SNS. In addition, these teams all managed a corporate Facebook page or a Twitter account; some of the team members were interacting with customers on these SNS.

\subsection{Interviews}

The 15 interviews were conducted individually as opposed to in a team setting so as to enable interviewees to answer as freely as possible. We offered a choice of conducting the interview on or outside of the worksite and during or outside of working hours; all interviewees chose to remain on their worksite during their work hours.

We began the interviews with an ice-breaking question reading: "Can you describe your position in the organization and your professional and academic background?" We then built our interview schedule questions so as to address our three research questions. We probed individuals about their online boundary 
management behaviors without bringing up OllierMalaterre et al.'s (2013) typology so that we would not influence interviewees' responses, and explored how well individuals' narration of their Facebook interactions matched the typology. Sample questions were: "How do you use social media with your coworkers, your supervisors, your customers?" and "What type of personal information do your coworkers share on social media?"

We included questions such as "How did the connections with your coworkers on social media take place?" and "Are there rules you tend to follow?" to assess what social norms interviewees felt they were creating, observing or following when interacting with their coworkers on SNS. Lastly, we framed open questions pertaining to outcomes on interpersonal relationships, without referring to any of the constructs reviewed above such as liking or jealousy, so that both positive and negative outcomes could emerge and include constructs we would not have identified. Sample questions were: "What are the advantages and disadvantages of connecting with your coworkers?", "How do you think that being connected with your coworkers on social media changes your relationship with them?", and "Can you give me an example of a situation when your connection to a coworker on a social media had negative consequences?"

The same co-author personally conducted the 15 interviews, which lasted an average of 45 to 60 minutes. All interviews were recorded, with the written consent of the interviewees and a guarantee of confidentiality and anonymity. Notes were taken during and following the interviews. We opted for a partial transcript of the interviews as opposed to a complete one, eliminating digressions that were not relevant to our objectives.

\subsection{Content analysis}

We began with an open coding of the transcripts, grouping similar excerpts and coding them with a brief description, such as "content of publication" or "annoyed by volume of publication" [47]. Then we proceeded to an axial coding where we reorganized the excerpts based on our literature review and looked out for emerging constructs [47]. We were able to regroup the 20 categories from the open coding in 6 broader themes such as "closeness" or "liking". The two authors each coded the 5 transcripts of the first team so as to strengthen the clarity of the coding scheme before the author who conducted the interviews went on with coding the 3 other teams' transcripts.

\section{Findings}

\subsection{Online boundary management strategies}

The 4 strategies theorized by Ollier-Malaterre et al. (2013) were identified in the interviews. The two strategies that came up the most were the hybrid and the content strategies. For instance: "Now it's so big that I'm very careful [about what I share on SNS] from a confidentiality point of view" and "I accept everyone [on Facebook]. On my personal page, I choose what I post carefully" (Director, Education and Events, 46, male). Only two participants said they did not do monitor at all what they published on SNS (i.e., an open strategy). However, the strategies were less clearcut than the ideal-types theorized by Ollier-Malaterre et al. (2013); for instance, the audience strategy was mostly used to exclude one type of professional contacts, customers, as opposed to excluding all professional contacts, including coworkers and supervisors: "I am friends on [Facebook] with some coworkers[but not customers]"(Owner, 41, female).

Interviewees' strategies also diverged from the 2013 typology because affordances enabling connections have evolved in recent years such that "connecting" on SNS now takes on different meanings. Some interviewees referred to dyadic two-way connections (e.g., Facebook friends) as examined in the 2013 typology, while others referred to one-way "Follow" connections (e.g., on Twitter, Instagram, or Facebook), and others still to group connections that do not imply dyadic disclosure of information (e.g., on LinkedIn or Facebook). As a result, the implications of connecting with professional contacts were more complex than theorized in Ollier-Malaterre et al. (2013) because allowing a professional contact to "follow" you does not imply that one has access to the follower's personal information, as the "friending" action may. Likewise, connecting with coworkers in a group does not entail that the coworkers access one's personal profile, "newsfeed" or "stories".

In addition, there is evidence that strategies could veer off course, either because the person's professional contacts did not take the hints as the person intended they would, or because the person was not very strategic about his or her own SNS behaviors. Audience strategies in particular were hard to maintain because customers kept connecting on interviewees' personal rather than work accounts. The following quote illustrates such a failure to maintain an audience strategy: "I created a [Facebook work account], but I don't know why people [i.e. customers and coworkers] are following me on my personal account" (Executive assistant, 41, female). Another interviewee struggled to 
implement her strategy: she intended to keep her Facebook personal but was accepting every friend request on Facebook in case they could be future customers. As a result, her Facebook was becoming both personal and professional without her realizing so.

\subsection{Emerging social norms}

Social norms, old and new, were manifest in our interviewees' answers. The first theme pertained to appropriate and inappropriate behaviors. The behaviors viewed as most inappropriate were 1) posting too much content on SNS and 2) behaving in an inauthentic way, when a gap between SNS postings and offline behaviors was observed. The following quotes illustrate these two norms: "I had employees who were a bit annoying [on Facebook], sharing what they ate, what they did... we don't need to know that. [...] It makes you want to avoid those people [...] It's like in real life, people who talk too much about themselves, they annoy you" (Owner, 41, female); "You know, sometimes some people on Facebook talk a lot and then you will meet them in real life and you will be like "oh ok, it's not the same person" and this makes me dislike more those people" (Sales consultant, 31, female). Regarding the initiations of SNS connections, sending an invitation was seen as a sensitive matter and potentially embarrassing for the recipient of the invitation: "I never invite anyone to be my friend [on Facebook] because when you invite someone, you put that person in a difficult situation where they have to accept your invitation" (Events coordinator, 41, female). Protecting one's LinkedIn existing contacts by refusing connections from strangers or distant professional contacts was deemed a polite thing to do: "It's rare that I accept someone on LinkedIn because I have a lot of people in my LinkedIn network who are corporate executives [...] we have a king of agreement between us" (Vice-President, 54, female).

The second theme pertained to SNS-based judgments. Interviewees were very ambivalent: they all agreed that people judge each other on SNS: "It's hard not to judge your colleagues on what they share on social media. It's the same thing in real life, but on social media, there are more opportunities to judge them" (Brand director, 45, male), "I would not post pictures of me wearing a bikini, I think it's unprofessional. I do not want to take the risk of losing the respect of my coworkers or customers" (Coordinator 31, female). However, they professed to not personally judge others on SNS: "I think people are not always careful on social media, but it does not change the way I see them" (Coordinator 31, female).

\subsection{Outcomes of SNS interactions on interpersonal relationships at work}

The outcomes reported by our interviewees were mostly positive, although they also accounted for the dark side of being connected with coworkers on SNS.

4.3. 1. Positive outcomes. Liking and closeness were the two main themes that came out of the interviews; closeness is a theme that emerged from the data and a new contribution of this study. Most comments related how interactions on SNS increased interpersonal liking and relational closeness. The following quotes illustrate these outcomes: "Sometimes, someone in the office I know a little bit [...] I see [on Facebook] that we have something in common [...] It might make me think "Ha, maybe I would like to have that person on my team" (Vice-President, 54, female); and "One benefit is that [your coworkers] learn to know you more as a person. Even if they do not know my children, they know my children [...]. For example, my boss will ask me about my children's activities. It brings us closer" (Director, 46, male). The frequency and ease of communication were instrumental in fostering closeness: "Of course we communicate a lot more often because we are friends on Facebook. Often it does not even relate to work" (Hairdresser, 18, female). Closeness was greater in informal work environments and smaller teams, as in this not-forprofit organization, the only team in our sample that had a non-work related Facebook private group to share jokes and memes: "We recently created a group page where we share stuff to brighten up the day [...] It's a way of keeping up with each other when we are not together at the office. (...) It's more fun [being connected on Facebook]. We feel closer to people. We are already close...we are a beautiful little family" (Communication coordinator, 27, female).

Respect for coworkers was also enhanced through SNS interactions, particularly because these interactions enabled individuals to learn more about their coworkers' skills. For instance, in this retail store specialized in equestrian equipment: "Of course, when I got here, I did not know my colleagues [...] I think being friends with them [on Facebook], I saw their publications about horses and everything, and I think that may have allowed me, you know, to see their skills [in the equestrian field]." (Sales consultant, 31, female). Interestingly, the interviewees who mentioned respect tended to be older than average.

A fourth benefit of connecting with coworkers on SNS was organizational citizenship behaviors oriented toward individuals (OCBI). Several interviewees had picked up more work for a colleague because they 
sensed that the colleague needed help, as illustrated in the following quote: "Yes, it has already happened that I took more work because I realized that a colleague was not well [because I saw it on Facebook]. It was not clear, but I saw she was quoting something sad" (Sales consultant, 29, female). Other helping behaviors were enabled by SNS postings which acted as signals that a certain subject could be discussed: "She or he is experiencing something difficult and [...] they put it on Facebook, meaning they want everyone to know, otherwise we do not put it on Facebook" (VicePresident, 54, female). Thus, SNS publications enabled coworkers to behave altruistically, either by offering emotional support, or by picking up tasks that were their coworkers' to perform rather than theirs.

4.3.2. Negative outcomes. However, interviewees also discussed challenges and drawbacks of connecting with coworkers on SNS. Sharing unprofessional information, and above all posting too much information, were perceived as "annoying" and led to disliking the culprits. Even sharing appropriate yet personal information led to decreased respect in the context of formal work environments and of hierarchical relationships: "Sometimes it can even be your superior who is not professional enough on a SNS. You have the CEO who comes to see you and then you are like "OK, I know what you did this weekend" (Executive assistant, 41, female).

SNS interactions also prompted envy in one of our teams, although this theme seemed to be taboo among interviewees as they only mentioned it very implicitly. Envy was particularly salient in the hairdressing team because of the inherent competition between quasiautonomous hairdressers, and of the visual nature of their work, which lends itself perfectly to SNS publications. Coworkers were jealous when one member of this team posted about an international show to which the others had not participated: "Somebody made [...] a good hairdressing show in Italy, they will put that on social media [...] and the other [employee] did not do it, he is going to see all the likes, and that everyone shares. So, of course..." (VicePresident, 54, female). Likewise, coworkers were envious of a hairdresser who posted before-after photos of her haircuts and had many likes from her customers:

"I was the only one who managed the Facebook page and the others ... well ... basically it was mainly for my projects. I was going to put pictures of my clients before / after. I had a lot of comments, "likes". I think the other girls were ... they saw that I had more customers ..." (Owner, 22, female).

\section{Discussion}

This exploratory study aimed at examining the ways in which SNS technology might frame interpersonal relationships at work when coworkers are connected with each other and share information that may be personal as well as work-related. Based on existing SNS research as well as on a typology of four online boundary management strategies that was theoretically proposed but not yet empirically tested [5, 26], this study extends our understanding of the psychological and social implications of connecting with coworkers on SNS.

\subsection{Theoretical contributions}

Our study is the first, to our best knowledge, to empirically test the typology of online boundary management strategies put forth by Ollier-Malaterre and colleagues. As such, it contributes to the social psychology and management literatures as well as to the growing body of interdisciplinary work on SNS. While we did identify each of the four strategies in our interviewees' narratives of their SNS behaviors, we found that almost all our interviewees managed the content of their information disclosure, using either the content or the custom strategies. In addition, the findings that initiating SNS connections was seen as a sensitive matter, and that protecting one's network was deemed appropriate, also indicate that open strategies may not be very widespread, or well accepted, in a work context.

We believe that this implies either that the open strategy may be receding among users of SNS due to an increased awareness of the public nature of open disclosures [17, 33], or that open strategies may be rare among working individuals who are connected with coworkers because individuals in that situation may behave in more careful ways. In addition, the four strategies identified in Ollier-Malaterre and colleagues' work were ideal-types [5]; indeed, we found evidence that the implications of connecting with professional contacts are more complex than initially theorized. As technology evolves quickly, other affordances such as Facebook and LinkedIn groups, and the ability to "follow" a person or a page (e.g., on Instagram and Facebook) rather than "friend" the person imply that one may be connected in very different ways on SNS. Being friends usually enables a reciprocal access to the other's information, unless the other enacts a custom strategy whereby s/he posts different information to different subgroups of friends. However, being connected with coworkers on a Facebook or LinkedIn group does not entail giving access to one's profile, 
page, "newsfeed", or "stories". Likewise, allowing a professional contact to "follow" you may be asymmetrical as it does not imply that one has access to the follower's personal information. Our findings therefore call for a revision and extension of OllierMalaterre and colleagues' theorizing that accounts for the various ways in which coworkers may connect on SNS.

Our study extends and renews work on the impact of the collision of professional and personal social worlds in cyberspace in a second way. The 2013 typology had proposed that the use of the four online boundary management strategies would be associated with positive, neutral, and negative effects on interpersonal respect and liking on the part of one's professional contacts. Based on theoretical arguments, these propositions have to our best knowledge not been tested yet, and they concern the average respect and liking that one receives from one's professional contacts, as opposed to dyadic respect and liking. Our study in which we were able to interview all the existing members of the teams we had selected enables us to empirically explore the collective and dyadic outcomes of being connected on SNS. We did find that interactions on SNS tended to increase interpersonal respect and liking. We were able to identify that respect is most increased by the discovery on SNS of coworkers' skills, and mostly in the eyes of older individuals, and that liking mostly depends on the content that is published and on the observance of social norms regarding appropriate volume and content of publications. In addition, we extend prior work on the outcomes of connecting with one's coworkers on SNS by identifying an emerging outcome, i.e. relational closeness, which is very sparsely discussed in the existing information systems, communications, social psychology and management literatures pertaining to SNS. The identification of this theme opens new vast new avenues for research. S. E. Seibert et al. [49] define closeness as follows: "Tie strength, or relationship closeness, consists of how often individuals communicate with one another and their level of emotional closeness". A rare investigation of closeness in the context of cyberspace interactions is $\mathrm{P}$. M. Valkenburg and J. Peter [50]'s study of the effect of teenagers online communication on relationship closeness. The study pointed out that the more online communications two friends had, the closer their relationship felt. Furthermore, the study noted that it was easier for teenagers to share intimate information online than it was offline. Thus, it appears that numerous communications on SNS encourage relationship closeness, as in clearly the case for our team in the not-for-profit sector.
Moreover, we were able to pinpoint another interesting positive outcome of SNS interactions, i.e. the organizational citizenship behaviors oriented toward individuals [51] that followed coworkers' publishing emotional content or content implying they were facing personal challenges. Our findings indicate that sharing an information on SNS or even simply implying that one is feeling sad or that something is wrong in one's life may signal to coworkers that the matter may be discussed and may encourage coworkers to pick up more work so as to help the individual in need.

Lastly, we uncover a negative outcome, envy, which has been sparsely examined in prior literature and only in the context of romantic rather than professional relationships [45]. Taken together, these findings have important theoretical implications for work looking at the impact of technology-supported collaboration on interpersonal attitudes in the workplace, such as respect, liking/disliking, and closeness, as well as on workplace behaviors and outcomes such as OCBI, and ultimately, performance at work.

The third contribution of our study pertains to the understanding of how social norms [27] play out in the new social space opened up by SNS, and more specifically on the emergence of new social norms for SNS interactions between coworkers. While some norms (e.g., pertaining to monitoring the volume and type of information one discloses) are in line with offline social norms, our study identifies a set of newer norms that frame social interactions in contemporary workplaces. Expectations for offline-to-online consistency, in particular, were widely shared in our sample and a basis for social judgments. In addition, several behaviors were clearly indicated by a majority of our interviewees as being either desirable (e.g., protecting one's LinkedIn contacts) or undesirable (e.g., publishing too much information or information deemed uninteresting, too personal, or inappropriate; sending embarrassing invitations). Therefore, our findings clarify that different norms may apply for SNS interactions compared with offline interactions.

It appears, therefore, that SNS, when used in a work context, may be viewed more as a front stage arena in which workplace and broader social norms apply [2] than as a backstage arena $[8,30]$ withdrawn from social expectations. Our findings could thus challenge the current transparency rhetoric promoted by firms such as Facebook, for instance [5], in that interviewees in our sample did not think socially acceptable to send invitations to everyone without thinking of the potential embarrassment this may cause, or to publish just about anything without 
assessing whether it may annoy one's coworkers and damage one's relationship with them. On the contrary, people were rather thoughtful about their behaviors and aware that SNS are a social arena where people have expectations and judge each other. Some ambivalence was expressed, as our interviewees were able to pinpoint the norms against which people were being judged on SMS, yet an equally strong norm among them was to profess being tolerant and personally refraining from judging others based on their SNS behaviors.

\subsection{Practical contributions}

There was a strong interest among our interviewees regarding what may constitute good and bad behaviors on SNS in a professional context. Clearly, many of us today are looking up for guidance and explanations about the social scripts that make up the netiquette, particularly on SNS that blend the personal and the professional. This study can be useful to individuals looking to understand what these social rules are and consequently, what effects their behavior on social network sites may entail for their relationships at work and professional reputation. At the group level, our study has implications for managers and team leaders who wish to leverage the bridging opportunities offered by SNS yet are wary of potential unintended consequences. Our findings suggest that rather than sending and accepting direct friend requests, which gives people access to each other's profiles, creating a group, such as a Facebook group, might help increase closeness among team members without violating old and new social norms or risking the disclosure of information that might be deemed inappropriate or too personal. We encourage managers and team leaders, as well as Human Resource and Organizational Development officers to discuss the difference between the ways in which coworkers may connect on SNS (i.e., reciprocal "friending" vs. asymmetrical "following" vs. group membership) and to explore which ones may be most beneficial, given the emerging social norms and the beneficial and detrimental outcomes we have identified in this study.

\subsection{Limitations and future research}

This research had some important limitations. First, the small size of our sample means that our findings cannot be generalized. Therefore, we call for future research to conduct quantitative studies examining SNS strategies, social norms, and outcomes on interpersonal relationships at work. In addition, a social desirability bias was obvious in our interviews, although we made sure to spend time and break the ice with each of our interviewees. We believe that the interviewees were careful not to reveal too much information that could have been incriminatory if revealed to their coworkers, whom they knew we would be interviewing as well. Almost nothing negative was ever said about coworkers, although we were able to pinpoint the themes of disliking and envy. In addition, no disparaging behavior on SNS was brought up, although these behaviors have been identified in larger samples which were quantitatively sampled [44]. It is therefore possible that our findings are downplaying the negative outcomes of connecting with one's coworkers on SNS. For future research, we suggest asking the ethical institutional board as well as interviewees for the permission to access the interviewees' SNS profiles themselves, and interviewing team members in a context such as an offsite training, in which the researcher has more time to gain the interviewees' trust and interviewees may be more detached from their immediate work context. A combination of face-to-face interviews and an electronic qualitative survey might also help to overcome social desirability.

\section{Conclusion}

This study has shed light on the psychological and social implications of technology, and in particular SNS, for interpersonal relationships in the workplace. We have discussed intricate online boundary management strategies that sometimes worked and sometimes veered off course, old and new social norms pertaining to interactions on SNS in a work context, and the benefits and pitfalls of leveraging SNS among coworkers. We hope that this exploratory study sparks interest for future research on these topics that are important for people and organizations, although still largely uncharted.

\section{References}

[1] J. Van Maanen, and E. G. Schein, "Toward a theory of organizational socialization", Research in Organizational Behavior (B. M. Staw, and L. L. Cummings, Eds), JAI Press, Greenwich, CT, 1979, vol.1, pp. 209-264.

[2] E. Goffman, The Presentation of self in everyday life (Doubleday Anchor Books), Garden City, New York, 1959.

[3] M. Weber, "Bureaucracy", Economy and Society: An Outline of Interpretive Sociology (G. Roth, and C. Wittich, Eds.), Bedminister Press, New York, 1968, pp. 956-1005. 
[4] J. Vitak, and N. B. Ellison, "'There's a network out there you might as well tap': Exploring the benefits of and barriers to exchanging informational and support-based resources on Facebook", New Media \& Society, 15(2), SAGE

Publications, 2013, pp. 243-259.

[5] A. Ollier-Malaterre, N. P. Rothbard, and J. M. Berg, "When worlds collide in cyberspace: How boundary work in online social networks impacts professional relationships", Academy of Management Review, 38(4), Academy of Management, 2013, pp. 645-659.

[6] M. Duggan et al., "Social Media Update 2014", Numbers, Facts and Trends Shaping the World, Pew Research Center, 2015.

[7] N. B. Ellison, C. Steinfield, and C. Lampe, "The benefits of Facebook "Friends:" Social capital and college students' use of online social network sites", Journal of ComputerMediated Communication, 12(3), International Communication Association, 2007, artic le 1.

[8] D. Boyd, "Social Network Sites: Public, Private, or What?"

http://kt.flexiblelearning.net.au/tkt2007/?page_id=28, Knowledge Tree, 2007.

[9] J. Donath, and D. Boyd, "Public displays of connection", BT Technology Journal, 22(4), Kluwer Academic Publishers, 2004, pp. 71-82.

[10] E. Litt, "Knock, Knock. Who's There? The Imagined Audience", Journal of Broadcasting \& Electronic Media, 56(3), 2012, pp. 330-345.

[11] S. Utz, "The function of self-disclosure on social network sites: Not only intimate, but also positive and entertaining self-disclosures increase the feeling of connection", Computers in Human Behavior, 45, 2015, pp. 110 .

[12] N. B. Ellison et al., "Cultivating Social Resources on Social Network Sites: Facebook Relationship Maintenance Behaviors and Their Role in Social Capital Processes", Journal of Computer-Med iated Communication, 19(4), 2014, pp. 855-870.

[13] C. Haythornthwaite, "Exploring multiplexity: Social network structures in a computer-supported distance learning class", The Information Society, 17(3), 2001.

[14] J. Peluchette, K. K. Van Eck, and J. Fertig, "A Facebook 'friend' Request from the Boss: Too Close for Comfort?", Business Horizons, 56(3), 2013, pp. 291-300.

[15] N. P. Rothbard, J. M. Berg, and A. Ollier-Malaterre, "OMG, my boss just Friended me: Hierarchical rank, selfdisclosure, and gender in online social networking", Academy of Management Conference, San Antonio, 2011.
[16] K. Lewis, J. Kaufman, and N. Christakis, "The taste for privacy: An analys is of college student privacy settings in an online social network", Journal Of Computer-Mediated Communication, 14, 2008, pp. 79-100.

[17] D. Trottier, "Interpersonal Surveillance on Social Media", Canadian Journal of Communication, 37(2), 2012, pp. 319-332.

[18] J. Van Dijck, "'You have one identity': performing the self on Facebook and LinkedIn", Media, Culture \& Society, 35(2), 2013, pp. 199-215.

[19] C. Fieseler, M. Meckel, and G. Ranzini, "Professional Personae - How Organizational Identification Shapes Online Identity in the Workplace", Journal of Computer-Mediated Communication, 20(2), 2015, pp. 153-170.

[20] A. Lampinen, S. Tamminen, and A. Oulasvirta, "All My People Right Here, Right Now: Management of Group Co-Presence on a Social Networking Site", Proceedings GROUP, ACM Press, 2009.

[21] M. Skeels, and J. Grudin, "When Social Networks Cross Boundaries: A Case Study of Workplace Use of Facebook and LinkedIn", Proceedings Group, Acm Press, 2009, pp. 95-104.

[22] B. Hogan, "The Presentation of Self in the Age of Social Media: Distinguishing Performances and Exhibitions Online", Bulletin of Science, Technology \& Society, 30(6), 2010, pp. 377-386.

[23] Z. Tufekci, "Can you see me now? Audience and disclosure management in online social network sites", Bulletin of Science and Technology Studies, 28(1), 2008, pp. 20-36.

[24] S. Zhao, S. Grasmuck, and J. Martin, "Identity construction on Facebook: Digital empowerment in anchored relationships", Computers In Human Behavior, 24(18161836), 2008

[25] F. Stutzman, and W. Hartzog, "Boundary Regulation in Social Media", Proceedings of ACM Conference on Computer Supported Cooperative Work, Seattle, WA, 2012, pp. $769-778$

[26] A. Ollier-Malaterre, and N. P. Rothbard, "Social Media or Social Minefield? Surviving in the New Cyberspace Era", Organizational Dynamics, 44(1), 2015.

[27] M. Sherif, The Psychology of Social Norms, Harper., New York, 1936.

[28] T. R. Tyler, and S. L. Blader, Cooperation in groups: Procedural justice, social identity, and behavioral engagement, Psychology Press, Philadelphia, PA, 2002. 
[29] T. R. Tyler, and S. L. Blader, Cooperation in groups: Procedural justice, social identity, and behavioral engagement, Psychology Press, Philadelphia, PA, 2000.

[30] D. Boyd, "Facebook's privacy train wreck: Exposure, invasion, and social convergence". http://www.danah.org/papers/FacebookPrivacyTrainwreck.p df, Convergence, 14(1), 2008, pp. 13-20.

[31] H. Lun, W. Tov, and L. Qiu, "Emotional Disclosure on Social Networking Sites: The Role of Network Structure and Psychological Needs", Computers in Human Behavior, 41, 2014, pp. 342-350.

[32] C. McLaughlin, and J. Vitak, "Norm evolution and violation on Facebook", New media \& society, 14(2), 2011, pp. 299-315.

[33] M. Madden, "Privacy management on social media sites", Pew Internet Report, 2012, pp. 1-20.

[34] M. Drouin et al., "Why do people lie online? "Because everyone lies on the internet"", Computers in Human Behavior, (64), 2016, pp. 134-142.

[35] S. Dutta, "What's your personal social media strategy?", Harvard Business Review Nov, 2010, pp. 127-130.

[36] S. Dreher, "Social Media and the World of Work: A Strategic Approach to Employees' Participation in Social Media", Corporate Communications: An International Journal, 19(4), 2014, pp. 344-356.

[37] D. Leidner, H. Koch, and E. Gonzalez, "Assimilating Generation Y IT New Hires into USAA's Workforce: The Role of an Enterprise 2.0 System", MIS Quarterly Executive, 9(4), 2010, pp. 229-242.

[38] H. Koch, E. Gonzalez, and D. Leidner, "Bridging the Work/social Divide: The Emotional Response to Organizational Social Networking Sites", European Journal of Information Systems, 21(6), 2012, pp. 699-717.

[39] P. Charoensukmongkol, "Effects of Support and Job Demands on Social Media Use and Work Outcomes", Computers in Human Behavior, 36, 2014, pp. 340-349.

[40] M. Moqbel, S. Nevo, and N. Kock, "Organizational Members' Use of Social Networking Sites and Job Performance: An Exploratory Study", Information Technology \& People, 26(3), 2013, pp. 240-264.

[41] M. Weisbuch, Z. Ivcevic, and N. Ambady, "'On being liked on the web and in the ""real world"": Consistency in first impressions across personal webpages and spontaneous behavior"", Journal of Experimental Social Psychology, 45, 2009, pp. 573-576.
[42] N. L. Collins, and L. C. Miller, "Self-disclosure and liking: A meta-analytic review", Psychological Bulletin, 116, 1994, pp. 457-475.

[43] J. McPherson, Miller, and L. Smith-Lovin, "Homophily in Voluntary Organizations: Status Distance and the Composition of Face-to-Face Groups", American Sociological Review, 52, 1987, pp. 370-379.

[44] R. N. Landers, and R. C. Callan, "Validation of the beneficial and harmful work-related social media behavioral taxonomies: Development of the work-related social media questionnaire", Social Science Computer Review, 32(5), 2014, pp. 628-646.

[45] A. Muise, E. Christofides, and S. Desmarais, "More information than you ever wanted: Does Facebook bring out the green-eyed monster of jealousy?", Cyberpsychology \& Behavior, 12(2), 2009, pp. 441-445.

[46] B. Glaser, and A. Strauss, The discovery of grounded theory, Weidenfeld and Nicolson, London, 1967.

[47] M. B. Miles, and A. M. Huberman, Qualitative Data Analysis - An Expanded Sourcebook, Sage, Thousand Oaks, CA, 1994.

[48] D. A. Gioia, K. G. Corley, and A. L. Hamilton, "Seeking Qualitative Rigor in Inductive Research", Organizational Research Methods, 16(1), 2013, pp. 15-31.

[49] S. E. Seibert, M. L. Kraimer, and R. C. Liden, "A Social Capital Theory of Career Success", The Academy of Management Journal, 44(2), 2001, pp. 219-237.

[50] P. M. Valkenburg, and J. Peter, "Preadolescents' and Adolescents' Online Communication and Their Closeness to Friends", Developmental Psychology, 43(2), 2007, pp. 267277.

[51] D. W. Organ, Organizational citizenship behavior: The good soldier syndrome, Lexington Books Lexington, MA, 1988.

Acknowledgment: This research was supported by the Social Sciences and Humanities Research Council of Canada. 